\title{
Evaluation of Breast Cancer Awareness among Female University Students in University of Sharjah, UAE
}

\author{
Abduelmula R. Abduelkarem*, Fatima Khalifa Saif, Salma Saif, Talal Ali Alshoaiby \\ College of Pharmacy, University of Sharjah, Sharjah, UAE \\ Email: ${ }^{*}$ aabdelkarim@sharjah.ac.ae
}

Received 22 December 2014; accepted 6 January 2015; published 19 January 2015

Academic Editor: Prof. Gerhard N. Schrauzer, University of California, USA

Copyright (C) 2015 by authors and Scientific Research Publishing Inc.

This work is licensed under the Creative Commons Attribution International License (CC BY). http://creativecommons.org/licenses/by/4.0/

(c) () Op Open Access

\section{Abstract}

Objective: The objectives of this study were to assess the knowledge of breast cancer among female students at the College of Pharmacy at the University of Sharjah, UAE, and to evaluate the impact of the intervention program designed by the researchers on the student's knowledge on the disease risk factors, screening methods, and their perception towards its treatment outcomes. Method: A cross-sectional questionnaire survey of a convenience sample of 166 pharmacy students $((n=110$; the 4th year) and $(n=56$; the 5th year $))$ in the University of Sharjah, Sharjah, UAE. The 26-item questionnaire covered the personal information and socio-demographic characteristics, breast cancer general knowledge, knowledge of breast cancer risk factors, knowledge of breast cancer symptoms and screening tests, and perception of management and outcomes of breast cancer. Key Findings: A total of 120 pharmacy students from the 4th year $(n=70)$ and the 5th year $(n=50)$ had completed the survey for the pre-intervention phase of the study. For the post intervention phase of the study, only 63 students from the 4th year and 48 students from the 5th year returned their completed questionnaire, giving a response rate of $90 \%$ and $96 \%$ respectively. Almost one quarter (59 (25.5)) of the students included in the study reported that they had a history of breast cancer in their family respectively. A high proportion (206 (89.2\%)) of the students from both levels showed their interest in participating in activities to promote breast awareness, despite the fact that almost three quarters $(161(70 \%))$ of the students reported that they had never been participated in any previous breast awareness programs. The awareness of students under investigation about self-examination was clearly improved at the end of the study period. Eighty $(66.7 \%)$ of the students from both levels reported that the breast self-examination is recommended for female "once a month". This figure was increased to $103(92.8 \%)$ post the intervention sessions ( $P$ value $\left.\chi^{2}<\mathbf{0 . 0 0 1}\right)$. Conclusion: The high incidence of breast cancer in the "Corresponding author. 
UAE may be attributed to the low level of awareness of the disease among females. Our findings can be used to promote discussion in the profession and with stakeholders about the future role of pharmacists in breast cancer care.

\section{Keywords}

Breast Cancer, Awareness, Sharjah, UAE, Knowledge and Perception

\section{Introduction}

Breast cancer is a malignant growth affecting the breast tissue, which may either affect the milk-producing ducts or the tubules carrying milk. There are two main histological types of breast cancer, namely, tubular and ductal carcinoma, and it may occur in males, though the incidence in females is much higher than in males [1]. Increasing age, family history, genetic factors, obesity, early menstruation, late menopause and nulliparity are all recognized as contributory factors [1].

Signs of breast cancer may include a palpable breast lump, nipple discharge and skin changes. Mammography detecting early signs of the disease is a valuable diagnostic test, while a pathological examination of a biopsy (fine needle aspiration (FNA), core biopsy, ultrasound-guided core biopsy, stereotactic biopsy, open excisional biopsy, and sentinel node biopsy) from a breast lump aids in differentiation of the types of cancer and survival rate. Breast cancer prognosis and treatment depend on tumor-node-metastasis staging, lympho-vascular spread, histological grade, hormone receptor status, comorbidities, and the patient's menopausal status. Generally, treatment includes surgical removal of the breast tissue, chemotherapy, hormone therapy, and radiotherapy [2].

Over the past two decades, female breast cancer has become a major health concern in both poor and rich countries due to its high incidence and associated mortality. It has been demonstrated in one particular study [3] that breast cancer is the most common cause of cancer death among women across the world. In 2008, breast cancer caused 480,000 deaths and about $70 \%$ of all cancer deaths occurred in low- and middle-income countries [1]. Based on the current estimate of an average annual increase in incidence ranging from $0.5 \%$ to $3 \%$ per year, the projected incidence increase in 2010 will be $1.4-1.5$ million [4]. More recently, it has been reported that breast cancer is the most prevalent cancer affecting women worldwide with 1.7 million new cases diagnosed in 2012, representing $25 \%$ of all cancers in women and recording the second leading cause of death among women [5].

Despite the fact that there is scary of data regarding breast cancer in the Arab world and developing countries, one can speculate that the incidence of breast cancer to be very high and is rising at a faster rate [3] [6]. In the United Arab Emirates (UAE), breast cancer is the most commonly diagnosed cancer in females, accounting for about $28 \%$ of female deaths [7]. The high incidence of breast cancer in the UAE may be attributed to the low level of awareness of the disease among females and the cultural taboos associated with this disease. Furthermore, it has been concluded in one particular study [8] that in most of the developing countries, patients will seek medical advice and treatment from such problem, when it is in an advanced stage and little or no benefit can be expected from any sorts of therapy.

The recent fall of death from breast cancer in western nations is particularly explained by earlier diagnosis as a result of early presentation. It has been demonstrated that delayed presentation of symptomatic breast cancer for several months ( $\geq 3$ months) from the first detection to the time of diagnosis and treatment has been associated with increased tumor size [9] and poor long-term survival [9] [10]. The negative sociocultural perception of breast cancer, strong beliefs in traditional medicine and perhaps strong religious beliefs are the main reasons for the delay in presentation in the Arab world and developing countries [11] [12]. It has been demonstrated that the majority of breast cancer cases in the UAE are diagnosed late with involvement of regional lymph nodes or distant metastasis [7].

Emphasis on early screening of breast cancer helps in earlier diagnosis and higher survival rates, and it has been estimated that a $100 \%$ survival rate is achievable for stages 0 and 1 of breast cancer cases [13]. Early diagnosis of female breast cancer can be achieved by mass screening, mammography, Clinical Breast Examination 
(CBE) and self-breast examination (SBE) or by the combination of three [14]. Even though mammography is the best choice for screening, breast self-examination is also equally important and beneficial for mass awareness, especially in countries with limited recourses or in a country where health care system still needs a lot of reforms and rearrangement, as in the case of many countries in the Arab world. It seems that pursuing a population based mass female screening program in most of developing countries is not a realistic approach. According to stepwise approach of Global Summit Panel 2002, SBE would be the approach for early detection [15]. However, lack of awareness, attitude and knowledge about the early detection of breast cancer and the benefits of screening tests is a real problem among women in developing countries and not very well documented. It has been reported that the public awareness of the importance of screening and early detection of breast cancer in the UAE women remains low [14], although increasing efforts from the Ministry of Health, public and private health sectors in the country, media and healthcare providers increase awareness of the public of this disease. Preventive behavior is essential for reducing cancer mortality. Knowledge is a necessary predisposing factor for behavioral change. Knowledge also plays an important role in improvement of health seeking behavior. Knowledge may not only dramatically improve the attitude, disbelieve and misconception, but also consequently enhance screening practice. That's why, to reduce the number of deaths from breast cancer, there was a shift in emphasis from breast self-examination to breast awareness after 1991 [16]. Besides, several studies also show that knowledgeable women and beliefs about breast cancer and its management may contribute significantly to medical help-seeking behaviors and increase their adherence to recommended breast cancer screening [17]-[19]. Furthermore, understanding the factors that influence patients' delay in seeking breast cancer treatment is therefore necessary to improve its treatment outcomes [20].

It is crucial for healthcare providers to educate the public about the importance of early detection of breast cancer, and engage in health awareness programs for breast cancer prevention, detection and treatment. Pharmacists, as a member of health care team, may play an important role in the improvement of public awareness about breast cancer. Providing information regarding mammography, education about available screening tests for breast cancer and designing pamphlets for women of the available tests and explaining the risk factors of this disease were recognized as an important role of pharmacists in breast cancer community care [14].

Fighting against cancers, specially breast cancer, is in the bottom of the priority list of the policy makers, though breast cancer is the second leading cause of cancer death among women worldwide. Considering the fact that breast cancer has become a global health care concern, several studies have been conducted worldwide to investigate women's knowledge and beliefs, and explore their awareness about breast cancer [17] [21]-[23]. However, none of these studies aimed at elicit awareness, attitude and knowledge of women about breast cancer in UAE. The objectives of this study were to assess the knowledge of breast cancer among female students at the College of Pharmacy at the University of Sharjah, UAE, and to evaluate the impact of the intervention program designed by the researchers on the student's knowledge on the disease risk factors, screening methods, and their perception towards its treatment outcomes.

\section{Method}

A cross-sectional study, using a validated questionnaire was used to conduct a face to face interview with each participant and to collect information (pre-intervention and post-intervention) from each student who agreed to take part in the study from the 4th and the 5th year pharmacy students, College of pharmacy, University of Sharjah, UAE. Students with no personal history of breast cancer and those able to understand the questionnaire were recruited for the study. Recruited students were asked to agree on a verbal informed consent before they allowed completing the study survey.

According to the university registration office and the college record system, the total number of the students registered in the 4th year and the 5th year pharmacy during the academic year 2013 was 110 and 56 students respectively. Based on the above database of student's registration, the minimum effective sample size was estimated to be 86 from the 4th year pharmacy students and 49 students of the 5th year using the online sample size calculator [24] with a confidence interval of $95 \%, 5 \%$ margin of error, and 50\% for the expected response distribution.

They survey was adapted and modified with permission from authors of one particular study [22]. The questionnaire with 26 items was designed to cover 5 sections: 1) personal information and socio-demographic characteristics (eight items: 1 - 8); 2) general knowledge (eight items: 9 - 16); 3) knowledge of breast cancer risk factors (eleven items: 17 - 27); 4) knowledge of breast cancer symptoms and screening tests (eight items: 28 - 
35); 5) perception of management and outcomes of breast cancer (eight items: 36 - 43). For most survey items, the respondents were asked to rate their response using the multiple choice options. A five point Likert type scale (from strongly agree to strongly disagree) was used to elicit the perception of the students towards management and treatment outcomes of breast cancer. There are many examples in the literature to support the use of such answer options in breast cancer studies [22] [23]. There was a section inviting comments at the end of questionnaire. (A copy of the questionnaire is available from the author).

There was no requirement to obtain ethical approval for such a study in the UAE. However, the approval was sought from the College of Pharmacy Research Committee. The study was carried out over a period of three months (from February 5th, 2014 to May 7th, 2014).

\subsection{Validity and Reliability Testing}

The validity of an instrument is the extent to which it actually measures what it is designed to measure. In survey work, this refers to the extent to which the questions collect accurate data relevant to the study's objectives. Evidence of validity may be gained through observation, expert and lay judgment, and empirical inquiry. Despite the fact that the tool used for this particular study was a validated survey and being extensively used in previous study [22] [23], to ensure the face validity of the instrument after being little bit modified to suit our target sample, the questionnaire was sent to two faculty member and one physician with a wide experience in survey design study. Furthermore, the researcher's three students from College of Pharmacy, University of Sharjah, UAE were also asked to read the survey and to give their feedback, if they will have any. All of their views and comments were considered and then incorporated into the final version of the questionnaire.

To assess test-retest reliability, the questionnaire was sent on two separate occasions to 10 students (not included in the final sample) randomly chosen in an area of study interest. The second response was elicited two weeks after the initial test. No problems were highlighted, and test-retest reliability was calculated using Spearman's correlation coefficient (r). The rho value was 0.73 , which implies an acceptable level of test re-test reliability. The alpha coefficient was 0.81 ; indicating that most of the items included make a valid contribution to the overall score.

For baseline purposes (pre-intervention phase of the study), the students under investigation were asked to complete the survey. During the intervention phase of the study, a clear and concise standardized information on different aspects of breast cancer were provided during the "Pharmacy Open Day" of the College to the participant students using different tools such as focus group lectures, distributing brochures that cover brief information on breast cancer such as definition, prevalence, signs and symptoms, stages, diagnosis, risk factors, treatment and prevention. Brief counseling session on how to conduct self-examination was carried out and pictures about breast cancer self-examination were distributed among the participants.

To increase and encourage students to participate in the study, T-shirts and mugs with special statements about breast cancer awareness written on them (Keep calm and support breast cancer, Early detection saves lives) were distributed as a gift to those who took part in the test your knowledge competition that was held near to our stand during the pharmacy open day event of the college. Furthermore, a Face book page with a name "Go pink" was created by the researchers and people, including the 4th and the 5th year pharmacy students of the college were invited to the page posted articles, posters and pictures related to breast cancer awareness. An instagram page was also developed and students under investigation were all invited this page. In this page we uploaded pictures and information regarding breast cancer and how to manage the condition.

\subsection{Data Analysis}

The participants' responses were encoded and the data were analyzed using Statistical Package for the Social Sciences (SPSS, version 20.0, Chicago, IL, USA). Descriptive analysis was used to calculate the proportion of each group of respondents answer on each statement in the questionnaire. Also, Chi Square test was used to identify any significant difference among the participants' responses regarding certain statements or questions in the questionnaire. Mann Whitney U test was used when it is possible. Furthermore, when analysing the responses data from the five-point scale regarding the perception of the students towards management and treatment outcomes of breast cancer, the responses were reduced to three categories: strongly agree/agree, neutral, and strongly disagree/disagree. This enabled more reader comprehensible confidence intervals for the relative pro- 
portions to be calculated. The level of statistical significance was set at $\mathrm{P}$ value of $<0.05$.

\section{Results}

A total of 120 pharmacy students from the 4 th year (70 students) and the 5 th year (50 students) had completed the survey for the pre-intervention phase of the study. For the post intervention phase of the study, only 111 pharmacy students from the 4th year (63 students) and the 5th year (48 students) returned their completed questionnaire, giving a response rate of $90 \%$ and $96 \%$ respectively. The average age of the students under investigation was $22.06 \pm 0.84$ years (range $=21-23$ years).

With regard to students' nationality, they were divided into four regions (Eastern Asia, Iraq and GCC countries, Arab countries in Africa, and Arab countries in Middle East). More than half 120 (51.9\%) of the students included in the study reported that they were from Arab countries in the Middle East region. The majority of the students from the 4th year $(126 ; 94.7 \%)$ and 5 th year $(92 ; 93.9 \%)$ reported that they were not involved in any type of work during the study period. Almost one quarter 35 (26.3) and 24 (24.5) of the investigated 4th and 5th year students reported that they have had a history of breast cancer in their family respectively. Interestingly, high proportion $206(89.2 \%)$ of the students from both levels showed their interest to participate in activities to promote breast awareness, despite the fact that almost 161 (70\%) of them reported that they have never been participated in any of previous breast awareness programs. Table 1 summarizes participant student's characteristics.

\section{General Knowledge of Breast Cancer}

When the participants included in the study were questioned if breast cancer only occurs in women, $80(60.2 \%)$ of the 4 th and $77(78.6 \%)$ of the 5 th year students answered no (P value $\left.\chi^{2}=0.01\right)$. When inquired if breast cancer is the number one type of cancer that occurs in the Arab world, 66 (49.6\%) of the 4th and $41(41.8 \%)$ of the 5 th year agreed this was the case $\left(\mathrm{P}\right.$ value $\left.\chi^{2}=0.27\right)$.

Before the intervention, close to half of our participants 54 (45\%) were aware of the symptoms of breast cancer; after the intervention, close to three quarters of the study population $81(73 \%)$ claimed that they do (P value $\left.\chi^{2}<0.001\right)$.

\section{Table 1. Participant student's characteristics.}

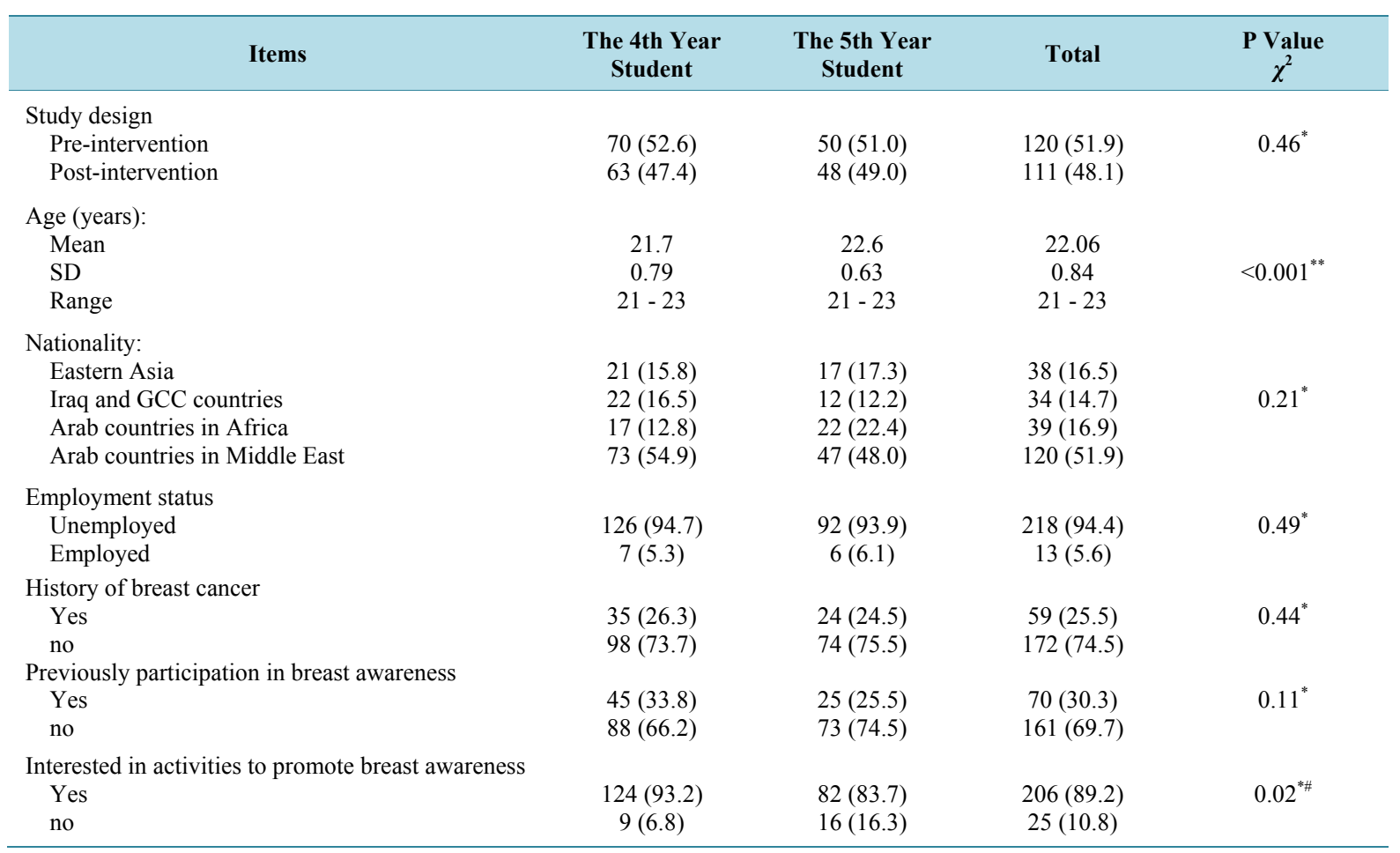

'One sample Chi-Square test $\left(\chi^{2}\right) ;{ }^{* *}$ Mann-Whitney U test; ${ }^{*}$ The significant of 0.02 is due to the 5 th year students responses $($ Std Residual $=1.7)$. 
Students from the 5th year were more confident in their ability to check their beast for any symptoms related to breast cancer. Seventy six $(57.1 \%)$ students from the 4 th year and $59(60.2 \%)$ from the 5 th year reported that they have enough confidence in checking their breast $\left(\mathrm{P}\right.$ value $\left.\chi^{2}=0.21\right)$.

As regard, the age in which breast cancer occurs more, close to three quarters of the study population before and after the intervention, $78(65 \%)$ and $84(75.7 \%)$ respectively, answered that breast cancer occurs more in the 31 - 49 years age group (P value $\chi^{2}=031$ ). Interestingly, there was significant difference $\left(\mathrm{P}\right.$ value $\left.\chi^{2}<0.001\right)$ in students under investigation answers when they were asked if only females are affected by breast cancer. The majority $90(81.1 \%)$ of the participants answered "no" after the intervention compared with only 67 (55.8\%) before the intervention. Table 2 summarizes the general knowledge of breast cancer among participants and according to their educational levels.

Table 2. General knowledge of breast cancer according to the educational levels and study design.

\begin{tabular}{|c|c|c|c|c|c|c|}
\hline \multirow[b]{2}{*}{ Item } & \multicolumn{3}{|c|}{ Education Levels } & \multicolumn{2}{|c|}{ Study Design } & \multirow[b]{2}{*}{$\begin{array}{c}\text { P Value } \\
\chi^{2}\end{array}$} \\
\hline & $\begin{array}{l}\text { The 4th Year } \\
\text { n }(\%)\end{array}$ & $\begin{array}{l}\text { The 5th Year } \\
\text { n }(\%)\end{array}$ & $\begin{array}{c}\text { P Value } \\
\chi^{2}\end{array}$ & $\begin{array}{l}\text { Pre-Intervention } \\
\text { n }(\%)\end{array}$ & $\begin{array}{c}\text { Post-Intervention } \\
\text { n (\%) }\end{array}$ & \\
\hline \multicolumn{7}{|c|}{$\begin{array}{l}\text { Only females are affected by breast } \\
\text { cancer }\end{array}$} \\
\hline Yes & $34(25.6 \%)$ & $15(15.3 \%)$ & & $38(31.7 \%)$ & $11(9.9 \%)$ & \\
\hline No & $80(60.2 \%)$ & $77(78.6 \%)$ & 0.011 & $67(55.8 \%)$ & $90(81.1 \%)$ & $<0.001$ \\
\hline Don't know & $19(14.3 \%)$ & $6(6.1 \%)$ & & $15(12.5 \%)$ & $10(9 \%)$ & \\
\hline \multicolumn{7}{|l|}{ Breast cancer can be transmitted } \\
\hline Yes & $2(1.5 \%)$ & $4(4.1 \%)$ & & $2(1.7 \%)$ & $4(3.6 \%)$ & \\
\hline No & $125(94 \%)$ & $91(92.9 \%)$ & 0.42 & $112(93.3 \%)$ & $104(93.7 \%)$ & 0.45 \\
\hline Don't know & $6(4.5 \%)$ & $3(3.1 \%)$ & & $6(5 \%)$ & $3(2.7 \%)$ & \\
\hline \multicolumn{7}{|c|}{$\begin{array}{l}\text { Breast cancer is number } 1 \text { in most of } \\
\text { Arab countries }\end{array}$} \\
\hline Yes & $66(49.6 \%)$ & $41(41.8 \%)$ & & $30(25 \%)$ & $77(69.4 \%)$ & \\
\hline No & $16(12 \%)$ & $9(9.2 \%)$ & 0.27 & $15(12.5 \%)$ & $10(9 \%)$ & $<0.001$ \\
\hline Don't know & $51(38.3 \%)$ & $48(49 \%)$ & & $75(62.5 \%)$ & $24(21.6 \%)$ & \\
\hline \multicolumn{7}{|l|}{ Awareness about symptoms } \\
\hline Yes & $74(55.6 \%)$ & $61(62.2 \%)$ & & $54(45 \%)$ & $81(73 \%)$ & \\
\hline No & $17(12.8 \%)$ & $11(11.2 \%)$ & 0.60 & $27(22.5 \%)$ & $1(0.9 \%)$ & $<0.001$ \\
\hline Don't know & $42(31.6 \%)$ & $26(26.5 \%)$ & & $39(32.5 \%)$ & $29(26.1 \%)$ & \\
\hline \multicolumn{7}{|c|}{$\begin{array}{l}\text { Are you confident that you know how to } \\
\text { check your breasts? }\end{array}$} \\
\hline Yes & $76(57.1 \%)$ & $59(60.2 \%)$ & & $43(35.8 \%)$ & $92(82.9 \%)$ & \\
\hline No & $57(42.9 \%)$ & $37(37.8 \%)$ & 0.21 & $77(64.2 \%)$ & $17(15.3 \%)$ & $<0.001$ \\
\hline Don't know & $0.0(0.0 \%)$ & $2(2 \%)$ & & $0(0.0 \%)$ & $2(1.8 \%)$ & \\
\hline \multicolumn{7}{|c|}{ Breast cancer occurs more at the age of } \\
\hline Under 30 years & $2(1.5 \%)$ & $5(5.1 \%)$ & & $3(2.5 \%)$ & $4(3.6 \%)$ & \\
\hline $31-49$ years & $97(72.9 \%)$ & $65(66.3 \%)$ & 0.23 & $78(65 \%)$ & $84(75.7 \%)$ & 0.13 \\
\hline Over 50 years & $34(25.6 \%)$ & $28(28.6 \%)$ & & $39(32.5 \%)$ & $23(20.7 \%)$ & \\
\hline \multicolumn{7}{|c|}{ How often do you check your breasts? } \\
\hline At least once a month & $22(16.5 \%)$ & $23(23.5 \%)$ & & $26(21.7 \%)$ & $19(17.1 \%)$ & \\
\hline Once a month to once a year & $31(23.3 \%)$ & $19(19.4 \%)$ & 0.40 & $16(13.3 \%)$ & $34(30.6 \%)$ & 0.006 \\
\hline Never & $80(60.2 \%)$ & $56(56.1 \%)$ & & $78(65 \%)$ & $58(52.3 \%)$ & \\
\hline \multicolumn{7}{|c|}{$\begin{array}{l}\text { Which of the following is not a treatment } \\
\text { used of breast cancer }\end{array}$} \\
\hline Surgery & $4(3 \%)$ & $2(2 \%)$ & & $4(3.3 \%)$ & $2(1.8 \%)$ & \\
\hline Chemotherapy & $4(3 \%)$ & $1(1 \%)$ & & $4(3.3 \%)$ & $1(0.9 \%)$ & \\
\hline Radiation Therapy & $2(1.5 \%)$ & $4(4.1 \%)$ & 0.05 & $6(5 \%)$ & $0.0(0.0 \%)$ & $<0.001$ \\
\hline Hormone Therapy & $23(17.3 \%)$ & $6(6.1 \%)$ & & $28(23.3 \%)$ & $1(0.9 \%)$ & \\
\hline Ultraviolet light therapy & $100(75.2 \%)$ & $85(86.7 \%)$ & & $78(65 \%)$ & $107(96.4 \%)$ & \\
\hline
\end{tabular}




\section{Knowledge of Breast Cancer Symptoms and Screening Test}

There was a clear significant difference $\left(\mathrm{P}\right.$ value $\left.\chi^{2}<0.001\right)$ in the students under investigation responses between the pre-intervention $(63 ; 52.5 \%)$ and post-intervention $(99 ; 89.2 \%)$ phase of the study regarding their knowledge of painless breast lump as a symptom of breast cancer.

The awareness of students under investigation about self-examination was clearly improved at the end of the study period. Eighty (66.7\%) of the students from both levels reported that the breast self-examination is recommended for female "Once a month". This figure was increased to $103(92.8 \%)$ post the intervention sessions (P value $\left.\chi^{2}<0.001\right)$. Interestingly, more than three quarter $103(77.4 \%)$ of the 4 th year students reported that self-examination of the breast should be conducted once a month compared to $80(81.6 \%)$ students from the 5th year reported that once a year is the recommended plan for breast self-examination (Table 3).

More than three quarters of the participants $92(76.7 \%)$ reported that pain in breast region was a sign/symptom of breast cancer during the pre-intervention phase of the study. However, this figure was dramatically increased into almost $100 \%$ at the end of the study period (P value $\chi^{2}<0.001$ ).

Respondent's opinion and views regarding clinical breast examination, Dimpling of breast skin, Change in the shape of breast, Nipple discharge, Lump under armpit according to educational levels and according to pre- and post-intervention design of the study are summarized in Table 3.

Table 3. Knowledge of breast cancer symptoms and screening tests according to education levels and study design.

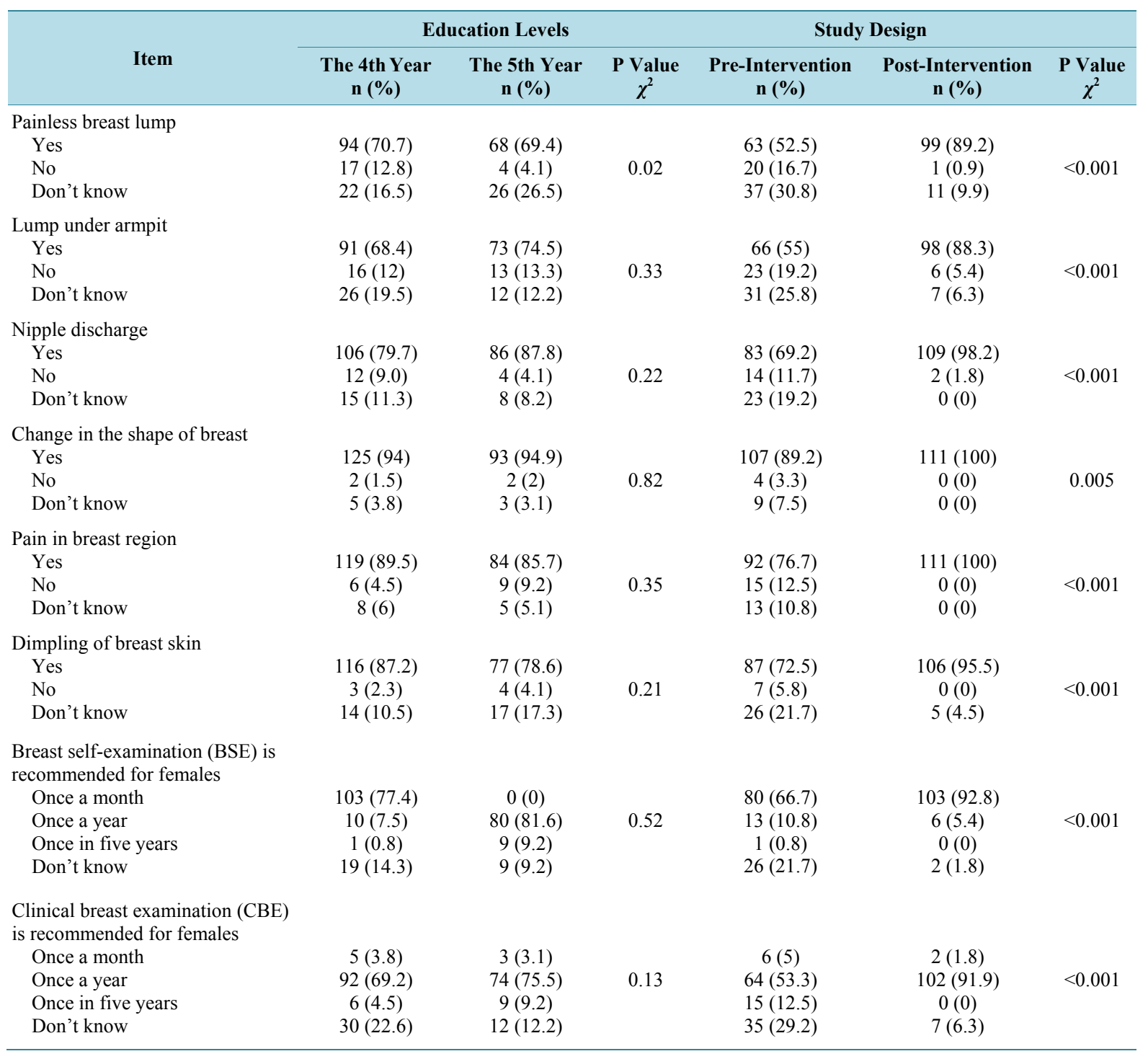




\section{Risk Factors of Breast Cancer}

Despite the fact of similar responses on the majority of risk factors of breast cancer items reported by the 4th year and the 5 th pharmacy students, there were a clear significant difference (P value $\left.\chi^{2}<0.001\right)$ between their answers reported on of the items related to risk factors of breast cancer in the pre-intervention and after the completion of breast cancer awareness program designed by the study researchers for the study purpose (Table 4).

Prior to the intervention, more than half of the examined participants $66(55 \%)$ and $83(69.2 \%)$ reported that they "don't know" as whether early appearance of menses or cigarette smoking increases the risk for developing of breast cancer respectively. However, the majority 97 (87.4\%) and 105 (94.6\%) of the interviewed students agreed on the statement that early onset of menses ( $<12$ years) and cigarette smoking increases the risk of breast cancer at the end of the study.

Breast feeding decreases the risk of breast cancer was reported by $49(40.8 \%)$ of the interviewed student at the baseline data (pre-intervention). Almost three quarter 83 (74.8\%) of the students reported that breast feeding decreases the risk of breast cancer after participation in the different awareness sessions conducted by the research over the study period. Responses of the study involved students on obesity, low fat diet, old age, family history of breast cancer, and hormone replacement therapy are all summarized in Table 4 .

\section{Perception of Management and Outcomes of Breast Cancer}

Twenty three (19.2\%) of participants were either strongly agreed or agreed on the statement that surgical removal of affected breast is the only treatment available. At the end of the study, the students under investigation either agreed or strongly agreed on the statement declined to $11(9.9 \%)(95 \% \mathrm{CI}=10.17-19.26)$. The majority $105(87.5 \%)$ of the participants (pre-interventions phase) and $110(99.1)(95 \% \mathrm{CI}=89.82-96.33)$ were either strongly agreed or agreed that having a mother or sister with breast cancer means you are more likely to get it. Seventy $(60.8 \%)$ of the students included in the study were either strongly disagreed or disagreed that treatment for breast cancer is embarrassing. Interestingly, the majority $100(90.1 \%)$ of the students either disagreed or strongly disagreed on the statement ( $\mathrm{P}$ value $\chi^{2}<0.001 ; 95 \% \mathrm{CI}=5.76-13.29$ ).

The perception of the interviewed students on early detection of breast cancer leads improved survival rate was not improved at the end of the study despite of the awareness intervention sessions. One hundred and twelve students (93.3\%) either strongly agreed or agreed on the above statement at the beginning of the study. This figure decreased into $99(89.2 \%)$ at the end of the study period ( $\mathrm{P}$ value $\left.\chi^{2}=0.5 ; 95 \% \mathrm{CI}=87.73-94.95\right)$. The perception of participants on the statements "a woman after receiving treatment for breast cancer can enjoy a good quality of life", "the treatment for breast cancer is a long and painful process", "treatments for breast cancer are more helpful to young people", and "treatment of breast cancer results in loss of physical beauty" are summarized in Table 5.

\section{Discussion}

In the Arab world, including the Gulf region, the incidence of female breast cancer is alarming and affecting a younger population compared to the West side of the world. In the Arab world countries, there are very few breast cancer awareness programs [14] [25]. Lack of knowledge about the breast cancer common risk factors and the understanding of the importance of breast self-examination were the recognized as the most findings in different studies conducted in Saudi Arabia different regions [25]-[27]. Several more studies assessed the awareness of breast cancer and the practice of breast self-examination among females of western [28] population, as well as Arab women in the Middle East [29] and in the Gulf region [25] [30]-[32]. However, few studies were conducted to address breast cancer among UAE females and none of the previous studies were designed to elicit the problem among university female students in Sharjah, UAE. Therefore the objective of this study is to investigate the level of breast cancer awareness among the pharmacy female students from fourth and fifth year of the college's five years study plan.

As regards general knowledge of breast cancer, the breast cancer cannot be transmitted was the most frequent knowledge identified by fourth and fifth year students, (94\%) and $(92.9 \%)$ respectively. This finding is consistent with what was reported by Hadi et al. [22] and reported that $91.5 \%$ of the students included in the study answered this question correctly.

Students from the 5 th year were more confident in their ability to check their beast for any symptoms related to 
Table 4. Risk factors of breast cancer according to the educational level of the study group.

\begin{tabular}{|c|c|c|c|c|c|c|}
\hline \multirow[b]{2}{*}{ Item } & \multicolumn{3}{|c|}{ Education Levels } & \multicolumn{2}{|c|}{ Study Design } & \multirow[b]{2}{*}{$\begin{array}{c}\text { P Value } \\
\chi^{2}\end{array}$} \\
\hline & $\begin{array}{l}\text { The 4th } \\
\text { Year } \\
\text { n (\%) }\end{array}$ & $\begin{array}{c}\text { The 5th } \\
\text { Year } \\
\text { n }(\%)\end{array}$ & $\begin{array}{c}\text { P Value } \\
\chi^{2}\end{array}$ & $\begin{array}{l}\text { Pre-Intervention } \\
\text { n (\%) }\end{array}$ & $\begin{array}{c}\text { Post-Intervention } \\
\text { n (\%) }\end{array}$ & \\
\hline \multicolumn{7}{|l|}{ Old age } \\
\hline Increases risk & $111(83.5)$ & $91(92.9)$ & \multirow{4}{*}{0.017} & $93(77.5)$ & $109(98.2)$ & \multirow{4}{*}{$<0.001$} \\
\hline Decreases risk & $1(0.8)$ & $0(0)$ & & $1(0.8)$ & $0(0)$ & \\
\hline No effect & $6(4.5)$ & $6(6.1)$ & & $10(8.3)$ & $2(1.8)$ & \\
\hline Don't know & $15(11.3)$ & $1(1)$ & & $16(13.3)$ & $0(0)$ & \\
\hline \multicolumn{7}{|c|}{ Family history of breast cancer } \\
\hline Increases risk & $129(97)$ & $96(98)$ & \multirow{4}{*}{0.455} & $114(95)$ & $111(100)$ & \multirow{4}{*}{0.058} \\
\hline Decreases risk & $0(0)$ & $0(0)$ & & $0(0)$ & $0(0)$ & \\
\hline No effect & $2(1.5)$ & $2(2)$ & & $4(3.3)$ & $0(0)$ & \\
\hline Don't know & $2(1.5)$ & $0(0)$ & & $2(1.7)$ & $0(0)$ & \\
\hline \multicolumn{7}{|l|}{ Cigarette smoking } \\
\hline Increases risk & $107(80.5)$ & $81(82.7)$ & \multirow{4}{*}{0.75} & $83(69.2)$ & $105(94.6)$ & \multirow{4}{*}{$<0.001$} \\
\hline Decreases risk & $2(1.5)$ & $3(3.1)$ & & $3(2.5)$ & $2(1.8)$ & \\
\hline No effect & $13(9.8)$ & $7(7.1)$ & & $17(14.2)$ & $3(2.7)$ & \\
\hline Don't know & $11(8.3)$ & $7(7.1)$ & & $17(14.2)$ & $1(0.9)$ & \\
\hline \multicolumn{7}{|l|}{ Low fat diet } \\
\hline Increases risk & $15(11.3)$ & $8(8.2)$ & \multirow{4}{*}{0.38} & $15(12.5)$ & $8(7.2)$ & \multirow{4}{*}{$<0.001$} \\
\hline Decreases risk & $63(47.4)$ & $56(57.1)$ & & $39(32.5)$ & $80(72.1)$ & \\
\hline No effect & $6(4.5)$ & $6(6.1)$ & & $12(10)$ & $0(0)$ & \\
\hline Don't know & $49(36.8)$ & $28(28.6)$ & & $54(45)$ & $23(20.7)$ & \\
\hline \multicolumn{7}{|c|}{ First child at late age ( $\geq 30$ years) } \\
\hline Increases risk & $71(53.4)$ & $68(69.4)$ & & $40(33.3)$ & $99(89.2)$ & \\
\hline Decreases risk & $1(0.8)$ & $2(2)$ & 0.04 & $1(0.8)$ & $2(1.8)$ & $<0.001$ \\
\hline No effect & $13(9.8)$ & $8(8.2)$ & & $19(15.8)$ & $2(1.8)$ & \\
\hline Don't know & $48(36.1)$ & $20(20.4)$ & & $60(50)$ & $8(7.2)$ & \\
\hline Early onset of menses & & & & & & \\
\hline Increases risk & $68(51.1)$ & $54(55.1)$ & & $25(20.8)$ & $97(87.4)$ & \\
\hline Decreases risk & $5(3.8)$ & $1(1)$ & 0.58 & $6(5)$ & $0(0)$ & $<0.001$ \\
\hline No effect & $15(11.3)$ & $12(12.2)$ & & $23(19.2)$ & $4(3.6)$ & \\
\hline Don’t know & $45(33.8)$ & $31(31.6)$ & & $66(55)$ & $10(9)$ & \\
\hline Late menopause $(>55$ & & & & & & \\
\hline Increases risk & $78(58.6)$ & $58(59.2)$ & & $43(35.8)$ & $93(83.8)$ & \\
\hline Decreases risk & $6(4.5)$ & $6(6.1)$ & 0.79 & $12(10)$ & $0(0)$ & $<0.001$ \\
\hline No effect & $14(10.5)$ & $7(7.1)$ & & $17(14.2)$ & $4(3.6)$ & \\
\hline Don’t know & $35(26.3)$ & $27(27.6)$ & & $48(40)$ & $14(12.6)$ & \\
\hline Use of oral contracep & & & & & & \\
\hline Increases risk & $97(72.9)$ & $83(84.7)$ & & $70(58.3)$ & $110(99.1)$ & \\
\hline Decreases risk & $2(1.5)$ & $1(1)$ & 0.21 & $3(2.5)$ & $0(0)$ & $<0.001$ \\
\hline No effect & $7(5.3)$ & $3(3.1)$ & & $9(7.5)$ & $1(0.9)$ & \\
\hline Don’t know & $27(20.3)$ & $11(11.2)$ & & $38(31.7)$ & $0(0)$ & \\
\hline Obesity & & & & & & \\
\hline Increases risk & $113(85)$ & $86(87.8)$ & & $92(76.7)$ & $107(96.4)$ & \\
\hline Decreases risk & $0(0)$ & $2(2)$ & 0.28 & $1(0.8)$ & $1(0.9)$ & $<0.001$ \\
\hline No effect & $2(1.5)$ & $1(1)$ & & $2(1.7)$ & $1(0.9)$ & \\
\hline Don't know & $18(13.5)$ & $9(9.2)$ & & $25(20.8)$ & $2(1.8)$ & \\
\hline Hormone replacemen & & & & & & \\
\hline Increases risk & $97(72.9)$ & $77(78.6)$ & & $71(59.2)$ & $103(92.8)$ & \\
\hline Decreases risk & $1(0.8)$ & $4(4.1)$ & 0.16 & $3(2.5)$ & $2(1.8)$ & $<0.001$ \\
\hline No effect & $2(1.5)$ & $1(1)$ & & $3(2.5)$ & $0(0)$ & \\
\hline Don't know & $33(24.8)$ & $16(16.3)$ & & $43(35.8)$ & $6(5.4)$ & \\
\hline Breast feeding & & & & & & \\
\hline Increases risk & $16(12)$ & $7(7.1)$ & & $19(15.8)$ & $4(3.6)$ & \\
\hline Decreases risk & $73(54.9)$ & $59(60.2)$ & 0.63 & $49(40.8)$ & $83(74.8)$ & $<0.001$ \\
\hline No effect & $14(10.5)$ & $11(11.2)$ & & $18(15)$ & $7(6.3)$ & \\
\hline Don't know & $30(22.6)$ & $21(21.4)$ & & $34(28.3)$ & $17(15.3)$ & \\
\hline
\end{tabular}


Table 5. Perception of management and outcomes of breast cancer.

\begin{tabular}{|c|c|c|c|c|c|}
\hline Items & $\begin{array}{c}\text { Pre-Intervention } \\
(\mathbf{1 2 0}) \\
\text { n (\%) }\end{array}$ & $\begin{array}{c}\text { Post-Intervention } \\
\text { (111) } \\
\text { n (\%) }\end{array}$ & $\begin{array}{c}\text { Total } \\
(\mathbf{n}=\mathbf{2 3 1}) \\
\mathbf{n}(\%)\end{array}$ & $\begin{array}{c}\text { P Value } \\
\chi^{2}\end{array}$ & $\begin{array}{l}\mathbf{9 5 \%} \text { CI for Single } \\
\text { Proportion for } \\
\text { Strongly } \\
\text { Agree/Agree } \\
\text { Responses }\end{array}$ \\
\hline \multicolumn{6}{|c|}{$\begin{array}{l}\text { Surgical removal of affected breast is the only } \\
\text { treatment available }\end{array}$} \\
\hline Strongly agree/agree & $23(19.2)$ & $11(9.9)$ & $34(14.7)$ & & \\
\hline Neutral & $7(5.8 \%)$ & $13(11.7 \%)$ & $20(8.7 \%)$ & 0.05 & $10.17-19.26$ \\
\hline Strongly disagree/disagree & $90(75 \%)$ & $87(78.4 \%)$ & $177(76.6 \%)$ & & \\
\hline \multicolumn{6}{|c|}{$\begin{array}{l}\text { Early detection of breast cancer leads improved } \\
\text { survival rate }\end{array}$} \\
\hline Strongly agree/agree & $112(93.3)$ & $99(89.2)$ & $211(91.3)$ & & \\
\hline Neutral & $4(3.3 \%)$ & $10(9.0 \%)$ & $14(6.1 \%)$ & 0.15 & $87.73-94.95$ \\
\hline Strongly disagree/disagree & $4(3.3 \%)$ & $2(1.8 \%)$ & $6(2.6 \%)$ & & \\
\hline \multicolumn{6}{|c|}{$\begin{array}{l}\text { Having a mother or sister with breast cancer } \\
\text { means you are more likely to get it }\end{array}$} \\
\hline Strongly agree/agree & $105(87.5)$ & $110(99.1)$ & $215(93.1)$ & & \\
\hline Neutral & $10(8.3 \%)$ & $0(0.0 \%)$ & $10(4.3 \%)$ & 0.002 & $89.82-96.33$ \\
\hline Strongly disagree/disagree & $5(4.2 \%)$ & $1(0.9 \%)$ & $6(2.6 \%)$ & & \\
\hline \multicolumn{6}{|c|}{$\begin{array}{l}\text { A woman after receiving treatment for breast } \\
\text { cancer can enjoy a good quality of life }\end{array}$} \\
\hline Strongly agree/agree & $76(63.3)$ & $109(98.2)$ & $185(80.1)$ & & \\
\hline Neutral & $32(26.7 \%)$ & $2(1.8 \%)$ & $34(14.7 \%)$ & $<0.001$ & $74.96-85.21$ \\
\hline Strongly disagree/disagree & $12(10.0 \%)$ & $0(0.0 \%)$ & $12(5.2 \%)$ & & \\
\hline \multicolumn{6}{|c|}{$\begin{array}{l}\text { The treatment for breast cancer is a long and } \\
\text { painful process }\end{array}$} \\
\hline Strongly agree/agree & $80(66.7)$ & $110(99.1)$ & $190(82.3)$ & & \\
\hline Neutral & $36(30.0 \%)$ & $1(0.9 \%)$ & $37(16.0 \%)$ & $<0.001$ & $77.35-87.15$ \\
\hline Strongly disagree/disagree & $4(3.3 \%)$ & $0(0.0 \%)$ & $4(1.7 \%)$ & & \\
\hline \multicolumn{6}{|c|}{$\begin{array}{l}\text { Treatments for breast cancer are more helpful to } \\
\text { young people }\end{array}$} \\
\hline Strongly agree/agree & $70(58.3)$ & $105(94.6 \%)$ & $175(15.8 \%)$ & & \\
\hline Neutral & $40(33.3 \%)$ & $2(1.8 \%)$ & $42(18.2 \%)$ & $<0.001$ & $70.26-81.26$ \\
\hline Strongly disagree/disagree & $10(8.3 \%)$ & $4(3.6 \%)$ & $14(6.1 \%)$ & & \\
\hline \multicolumn{6}{|c|}{ Treatment for breast cancer is embarrassing } \\
\hline Strongly agree/agree & $22(18.3)$ & $0(0.0 \%)$ & $22(9.5 \%)$ & & \\
\hline Neutral & $25(20.8 \%)$ & $11(9.9 \%)$ & $36(15.6 \%)$ & $<0.001$ & $5.76-13.29$ \\
\hline Strongly disagree/disagree & $73(60.8 \%)$ & $100(90.1 \%)$ & $173(74.9 \%)$ & & \\
\hline \multicolumn{6}{|c|}{$\begin{array}{l}\text { Treatment of breast cancer results in loss of } \\
\text { physical beauty }\end{array}$} \\
\hline Strongly agree/agree & $68(56.7)$ & $71(64.0 \%)$ & $139(60.2)$ & & \\
\hline Neutral & $31(25.8 \%)$ & $34(30.6 \%)$ & $65(28.1 \%)$ & 0.017 & $53.89-66.45$ \\
\hline Strongly disagree/disagree & $21(17.5 \%)$ & $6(5.4 \%)$ & $27(11.7 \%)$ & & \\
\hline
\end{tabular}

breast cancer. Seventy six $(57.1 \%)$ students from the 4 th year and $59(60.2 \%)$ from the 5 th year reported that they have enough confidence in checking their breast.

Despite the fact of non-significant difference ( $\mathrm{P}$ value $\chi^{2}=0.21$ ) in the responses of the students from the 4th year $(57 ; 57.1 \%)$ and the 5 th year $(59 ; 60.2 \%)$ when they were asked about their confident to check their breast for any sign of cancer, fifth year students were more positive regarding their ability to check their breasts, this could be attributed to the fact of prior exposure to material dealing with breast cancer as part of their curriculum. The importance of exposure to breast cancer educational material and awareness interventions about breast cancer were also demonstrated by the findings of this study. Only $43(35.8 \%)$ of the participants reported that they have enough confident to check their breasts at the beginning of the study, compared to $92(82.9 \%)$ after the completion of awareness program (brochures and the illustrating pictures about breast cancer self-examination) that was distributed by the researchers over the study period. 
Regarding awareness of breast cancer warning signs, breast lump was the most frequently symptom identified by almost half of participants (50.5\%) in the study conducted on Saudi females in Jeddah [33]. The result of Saudi females in Jeddah is in disagreement with that was reported by Malaysia study [22] and the results the present study. The most identified symptom by the students in Malaysia and this study was the change in shape of the breast, $81 \%$ and $89.2 \%$ respectively. Interestingly, in the present study the awareness materials about the breast cancer were effective in improving the knowledge of breast cancer signs and symptoms among participants. Almost $100 \%$ of the students under investigation were able to identify that change in the shape of the breast and pain in breast as the most important sign/symptom for the breast cancer problem.

In the present study, it was found that although the majority of participants were aware of the breast self-examination for breasts in females, the majority of participants are neither aware of the frequency of performing breast self-examination. More than three quarter 103 (77.4\%) of 4th year pharmacy students reported that it should be recommended for once a month. On the other hand, $80(81.6 \%)$ from the 5 th year reported that it should be recommended for once a year. These findings are congruent with previous studies investigating awareness and knowledge of breast cancer and practices of breast self-examination among women and university students in Saudi Arabia [26] [32]-[34].

Regarding awareness of breast cancer risk factors, the majority of participants (97\%) fourth year and (98\%) fifth year reported that having family history with breast cancer is considered a risk factor that might lead to developing breast cancer among the family members. This result is similar to those results presented in Saudi Arabia study [33] and Malaysia study. (91\%) [22], which revealed that more than half (57.5\%) of females Saudi and the majority (91\%) of Malaysia females included in the study knew about family history and having a close relative with breast cancer as established risk factors for the disease. More than half 71 (59.2\%) and 70 (58.3) of the students under investigation were aware of hormone replacement therapy and uses of oral contraceptives as other risk factors of breast cancer respectively. However, knowledge of other risk factors of breast cancer was limited as only few females knew that early onset of menses $(<12$ years) $(25 ; 20.8 \%)$, first child at late age ( $\geq 30$ years) $(40,33.3 \%)$, late menopause ( $>55$ years) $(43 ; 35.8 \%)$, and cigarette smoking $(83 ; 69.2 \%)$ are risk factors of breast cancer. Intervention awareness program was effective in improving participants awareness of the risk factors associated with breast cancer. Almost three quarter $(80,72.1 \%)$ and the majority $(105 ; 94.6 \%)$ of the interviewed students were able to identify low fat diet and cigarette smoking as important factor to decrease and increase the risk of developing breast cancer respectively, which is a contrast to the results obtained prior to the intervention, where only $39(32.5 \%)$ and $83(69.2 \%)$ of the students included in the study were able to identify the impact of low fat diet and cigarette smoking on developing of breast cancer (P value $\chi^{2}<0.001$ ).

The vast majority of our study participants had correct beliefs and positive perception about breast cancer management and its outcomes. At the beginning of our study, most of the studied students (93.3\%) reported that early detection of breast cancer leads to improve survival rate. However, 76 (63.3\%), 80 (66.7\%), and 70 (58.3\%) were either strongly agreed or agreed that a woman after receiving treatment for breast cancer can enjoy a good quality of life, the treatment for breast cancer is a long and painful process, and treatments for breast cancer are more helpful to young people respectively. Intervention awareness programs has a dramatic effect on the participants perception regarding a woman after receiving treatment for breast cancer can enjoy a good quality of life, the treatment for breast cancer is a long and painful process, and treatments for breast cancer are more helpful to young people. The majority of participants reported that either agreed or strongly agreed with the statements such as intervention awareness programs has a dramatic effect on the participants perception regarding a woman after receiving treatment for breast cancer can enjoy a good quality of life $(109 ; 98.2 \%)$, the treatment for breast cancer is a long and painful process $(110 ; 99.1 \%)$, and treatments for breast cancer are more helpful to young people $(105 ; 94.6 \%)$. One can contemplate that such observable changes may be attributed to the contents of the brochures that were distributed during the intervention awareness program, which contained detail explanation about how to manage and what are the outcomes of breast cancer. Overall, the intervention helped improve the participant's response to the survey questions; this could indicate that breast cancer campaign can improve the prognosis and survivability.

Study findings directed the light on the importance of raising the level of public awareness about breast cancer to overcome an ever-increasing burden of this disease and reduce the number of new cases that put the UAE at the top of the scale among the other countries with a high rate of breast cancer sufferers. Proper counseling should be routinely given by healthcare providers within hospitals and clinics to improve breast cancer knowledge. The primary goal is to improve the survival rate by promoting early detection and medical help-seeking 
behaviors among females. The study was conducted among the pharmacy students of University of Sharjah only and therefore might not be a representative of all universities across the UAE.

\section{Conclusion}

Despite the limitations of this cross sectional survey study (time constrain, reluctant of some students to repeat felling the form, and lack of research attitude among university female students), the findings of the present study provide some insights into changes in students' perception at the baseline and at the end of the study period. Findings indicated that levels of awareness of breast cancer of studied female students, i.e. knowledge of breast cancer warning signs, risk factors, screening program and breast self-examination, were very inadequate at the beginning of the study. Surprisingly, most of the findings after the awareness program designed for the purpose of the research study had a dramatic change which indicated that the breast cancer awareness were more likely to be effective and have a larger impact. Indeed, the focus of primary health care providers should be to raise awareness about breast care, not only for females in communities, but also for future health care providers, especially the newly graduates from the health and medical related schools.

\section{Acknowledgements}

First of all, we would like to thank our supervisor Prof. Abdulmawla Abdulkarem, whose help, advice and supervision was invaluable. He inspired us greatly to work in this project and we appreciate his valuable guidance and support till the end of our study. Also we would like to thank all of the students who helped us to accomplish our study and who answered our questionnaires. Our thanks go to our college administration for their allowance to participate in the open day to do our study intervention phase. Finally, we would like to thanks our parents for their great help and encouragement through the entire period of the study.

\section{References}

[1] World Health Organization (WHO) (2006) Cancer Fact Sheet No. 297. http://www.who.int/mediacentre/factsheets/fs297/en/index.html

[2] Maughan, K.L., Lutterbie, M.A. and Ham, P.S. (2010) Treatment of Breast Cancer. American Family Physician, 81, 1339-1346.

[3] Bray, F., MacCarron, P. and Maxwell Parkin, D. (2004) The Changing Global Patterns of Female Breast Cancer Incidence and Mortality. Breast cancer Research, 6, 229-239. http://dx.doi.org/10.1186/bcr932

[4] Smith, R.A., Caleffi, M., Albert, U.-S., Chen, T.H.H., duffy, S.W., et al. (2006) Breast Cancer in Limited Resource Countries: Early Detection and Access to Care. The Breast Journal, 12, S16-S26.

[5] Cancer Research UK (2014) Breast Cancer Incidence Statistics. http://info.cancerresearchuk.org/cancerstats/types/breast/incidence/

[6] Parkin, D.M., Whelan, S.L., Ferlay, J., Raymond, L. and Young, J. (1997) Cancer Incidence in Five Continents. Vol. 8, IARC Press, Lyon.

[7] Al-Sharbatti, S.S., Shaikh, R.B., Mathew, E. and Al-Biate, M.A.S. (2013) Breast Self-Examination Practice and Breast Cancer Risk Perception among Female University Students in Ajman. Asian Pacific Journal of Cancer Prevention, 14, 4919-4923. http://dx.doi.org/10.7314/APJCP.2013.14.8.4919

[8] Ibrahim, O. and Ibrahim, R. (2013) Community Pharmacists' Involvement in Breast Cancer Health Promotion in United Arab Emirates (UAE). American Journal of Pharmacology and Toxicology, 8, 155-163. http://dx.doi.org/10.3844/ajptsp.2013.155.163

[9] Richards, M.A., Westcombe, A.M., Love, S.B., Littlejohns, P. and Ramirez, A.J. (1999) Influence of Delay on Survival in Patients with Breast Cancer: A Systematic Review of the Literature. The Lancet, 353, 1119-1126. http://dx.doi.org/10.1016/S0140-6736(99)02143-1

[10] Rossi, S., Cinini, C., Di Pietro, C., Lombardi, C.P., Crucitti, A., Bellantone, R. and Crucitti, F. (1990) Diagnostic Delay in Breast Cancer: Correlation with Disease Stage and Prognosis. Tumori, 76, 559-562.

[11] Rashidi, A. and Rajaram, S.S. (2000) Middle Eastern Asian Islamic Women and Breast Self-Examination: Needs Assessment. Cancer Nursing, 23, 64-70. http://dx.doi.org/10.1097/00002820-200002000-00010

[12] Rajaram, S.S. and Rashidi, A. (1999) Asian-Islamic Women and Breast Cancer Screening: A Socio-Cultural Analysis. Women \& Health, 28, 45-58. http://dx.doi.org/10.1300/J013v28n03 04 
[13] Venkatramana, M., Sreedharan, J., Muttappallymyalil, J. and Thomas, M. (2011) Opinion of Nurses Regarding Breast Cancer Screening Programs. Indian Journal of Cancer, 48, 423-427. http://dx.doi.org/10.4103/0019-509X.92262

[14] Bener, A., Honein, G., Carter, A., Da'ar, Z., Miller, C. and Dunn, E. (2002) The Determinants of Breast Cancer Screening Behavior: A Focus Group Study of Women in the United Arab Emirates. Oncology Nursing Forum, 29, E91-E98. http://dx.doi.org/10.1188/02.ONF.E91-E98

[15] Anderson, B.O., Braun, S., Lim, S., Smith, R.A., Taplin, S. and Thomas, D.B. (2003) Early Detection of Breast Cancer in Countries with Limited Resources. The Breast Journal, 9, S51-S59. http://dx.doi.org/10.1046/j.1524-4741.9.s2.4.x

[16] English, J. (2003) Importance of Breast Awareness in Identification of Breast Cancer. Nursing Times, 99, 18-19.

[17] Odusanya, O.O. and Tayo, O.O. (2001) Breast Cancer Knowledge, Attitudes and Practice among Nurses in Lagos, Nigeria. Acta Oncologica, 40, 844-848. http://dx.doi.org/10.1080/02841860152703472

[18] Sadler, G.R., Ko, C.M., Cohn, J.A., White, M., Weldon, R. and Wu, P. (2007) Breast Cancer Knowledge, Attitudes, and Screening Behaviors among African American Women: The Black Cosmetologists Promoting Health Program. BMC Public Health, 7, 57. http://dx.doi.org/10.1186/1471-2458-7-57

[19] Grunfeld, E.A., Ramirez, A.J., Hunter, M.S. and Richards, M.A. (2002) Women's Knowledge and Beliefs Regarding Breast Cancer. British Journal of Cancer, 86, 1373-1378. http://dx.doi.org/10.1038/sj.bjc.6600260

[20] Luquis, R.R. and Villanueva Cruz, I.J. (2006) Knowledge, Attitude and Perceptions about Breast Cancer and Breast Cancer Screening among Hispanic Women Residing in South Central Pennsylvania. Journal of Community Health, 31, 25-42. http://dx.doi.org/10.1007/s10900-005-8187-x

[21] Okobia, M.N., Bunker, C.H., Okonofua, F.E. and Osime, U. (2006) Knowledge, Attitude and Practice of Nigerian Women towards Breast Cancer: A Cross-Sectional Study. World Journal of Surgical Oncology, 4, 11. http://dx.doi.org/10.1186/1477-7819-4-11

[22] Hadi, M.A., Hassali, M.A., Shafie, A.A. and Awaisu, A. (2010) Evaluation of Breast Cancer Awareness among Female University Students in Malaysia. Pharmacy Practice (Internet), 8, 29-34.

[23] Hadi, M.A., Hassali, M.A., Shafie, A.A. and Awaisu, A. (2010) Knowledge and Perception of Breast Cancer among Women of Various Ethnic Groups in the State of Penang: A Cross-Sectional Survey. Medical Principles and Practice, 19, 61-67. http://dx.doi.org/10.1159/000252837

[24] Raosoft. An Online Sample Size Calculator. http://www.ezsurvey.com/samplesize

[25] Abdel Hadi, M. (2000) Breast Cancer Awareness among Health Professionals. Annals of Saudi Medicine, 20, $135-136$.

[26] Alam, A. (2006) Knowledge of Breast Cancer and Its Risk and Protective Factors among Women in Riyadh. Annals of Saudi Medicine, 26, 272-277.

[27] Dandash, K. and Al-Mohaimeed, A. (2007) Knowledge, Attitudes, and Practices Surrounding Breast Cancer and Screening in Female Teachers of Buraidah, Saudi Arabia. International Journal of Health Sciences, 1, 61-71.

[28] Linsell, L., Burgess, C. and Ramirez, A.J. (2008) Breast Cancer Awareness among Older Women. British Journal of Cancer, 99, 1221-1225. http://dx.doi.org/10.1038/sj.bjc.6604668

[29] Montazeri, A., Vahdaninia, M., Harirchi, I., Harirchi, A.M., Sajadian, A., Khaleghi, F., et al. (2008) Breast Cancer in Iran: Need for Greater Women Awareness of Warning Signs and Effective Screening Methods. Asia Pacific Family Medicine, 7, 6. http://dx.doi.org/10.1186/1447-056X-7-6

[30] Alharbi, N., Alshammari, M., Almutairi, B., Makboul, G. and El-Shazly, M. (2012) Knowledge, Awareness, and Practices Concerning Breast Cancer among Kuwaiti Female School Teachers. Alexandria Journal of Medicine, 48, 75-82.

[31] Bener, A., El Ayoubi, H., Moore, M., Basha, B., Joseph, S. and Chouchane, L. (2009) Do We Need to Maximize the Breast Cancer Screening Awareness? Experience with an Endogamous Society with High Fertility. Asian Pacific Journal of Cancer Prevention, 10, 599-604.

[32] Jahan, S., Al-Saigul, M. and Abdelgadir, M.H. (2006) Breast Cancer: Knowledge, Attitudes and Practices of Breast Self-Examination among Women in Qassim Region of Saudi Arabia. Saudi Medical Journal, 27, 1737-1741.

[33] Radi, S.M. (2013) Breast Cancer Awareness among Saudi Females in Jeddah. Asian Pacific Journal of Cancer Prevention, 14, 4307-4312. http://dx.doi.org/10.7314/APJCP.2013.14.7.4307

[34] Habib, F., Salman, S., Safwat, M. and Shalaby, S. (2010) Awareness and Knowledge of Breast Cancer among University Students in Al Madina Al Munawara Region. Middle East Journal of Cancer, 1, 159-166. 
Scientific Research Publishing (SCIRP) is one of the largest Open Access journal publishers. It is currently publishing more than 200 open access, online, peer-reviewed journals covering a wide range of academic disciplines. SCIRP serves the worldwide academic communities and contributes to the progress and application of science with its publication.

Other selected journals from SCIRP are listed as below. Submit your manuscript to us via either submit@scirp.org or Online Submission Portal.
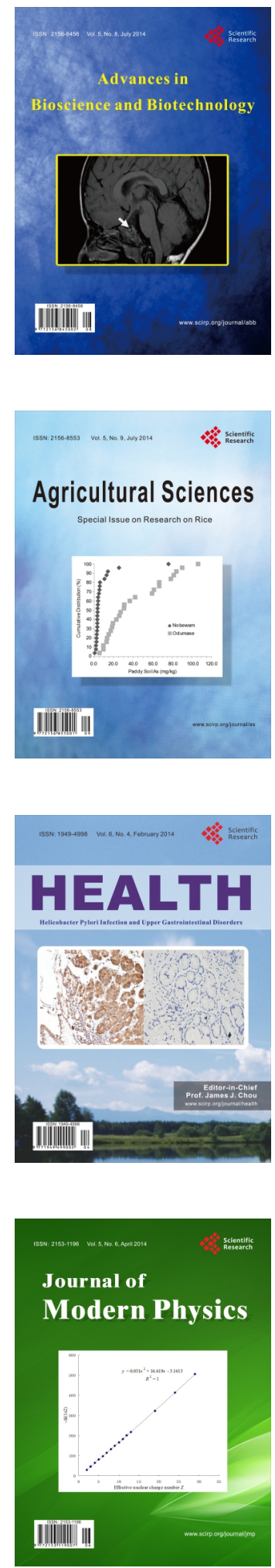
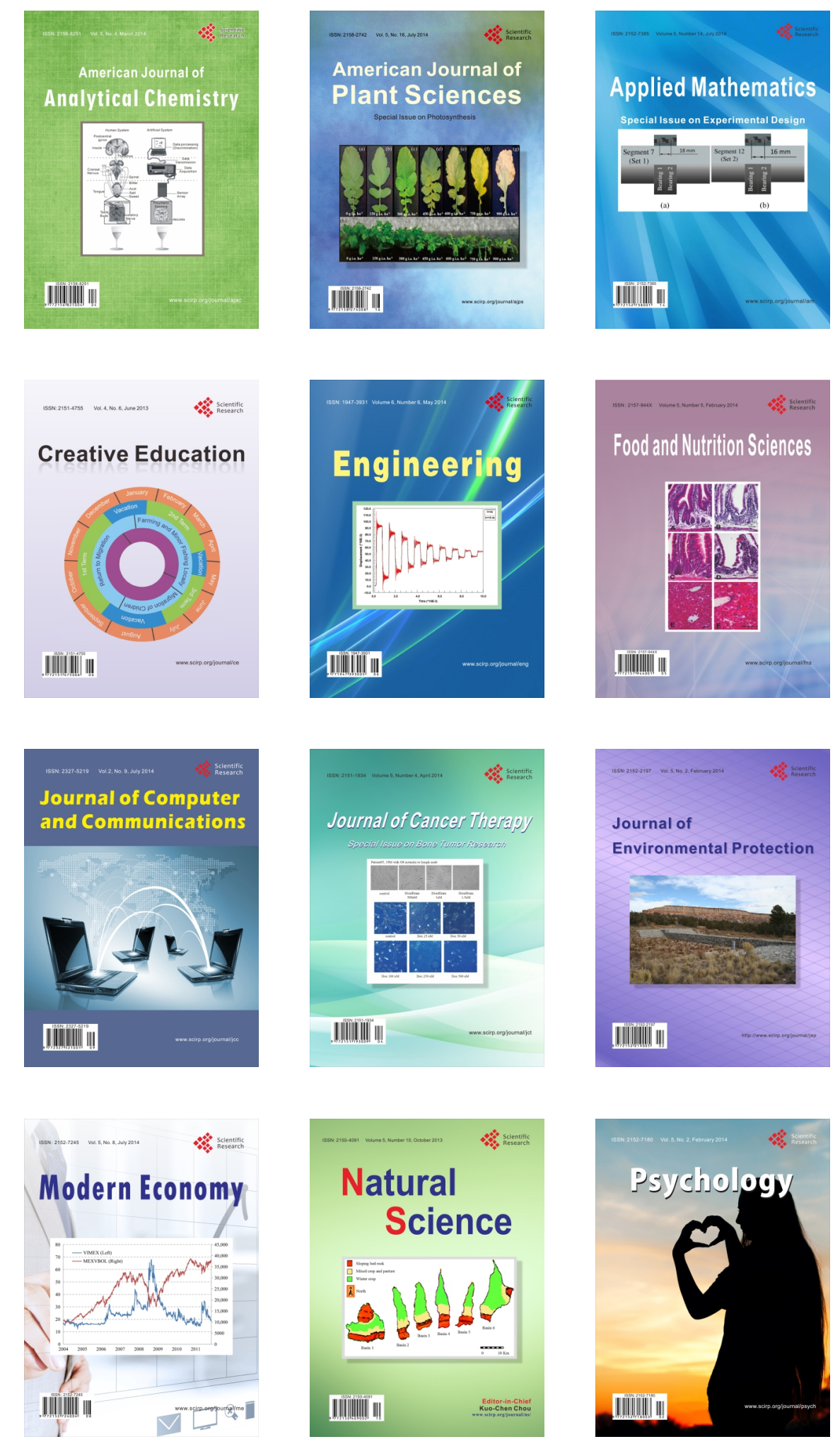